\title{
Surface high-resolution temperature forecast in southern Italy
}

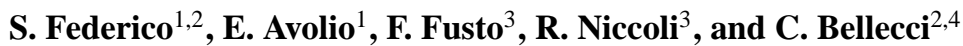 \\ ${ }^{1}$ ISAC-CNR, UOS of Lamezia Terme, Lamezia Terme (CZ), Italy \\ ${ }^{2}$ CRATI, Rende (CS), Italy \\ ${ }^{3}$ ARPACal, Catanzaro, Italy \\ ${ }^{4}$ Engeenering Department, University of "Tor Vergata", Rome, Italy
}

Received: 24 December 2010 - Revised: 15 July 2011 - Accepted: 31 July 2011 - Published: 16 August 2011

\begin{abstract}
Since June 2008, 1-h temperature forecasts for the Calabria region (Southern Italy) are issued at $2.5 \mathrm{~km}$ horizontal resolution at CRATI/ISAC-CNR. Forecasts are available online at http://meteo.crati.it/ previsioni.html (every 6-h). This paper shows the forecast performance out to three days for one climatological year (from 1 December 2008 to 30 November 2009, 365 run) for minimum, mean and maximum temperature. The forecast is evaluated against gridded analyses at the same horizontal resolution.

Gridded analysis is based on Optimal Interpolation (OI) and uses a de-trending technique for computing the background field. Observations from 87 thermometers are used in the analysis system.

In this paper cumulative statistics are shown to quantify forecast errors out to three days.
\end{abstract}

\section{Introduction}

This paper investigates the performance of the highresolution $(2.5 \mathrm{~km}$ horizontal resolution) operational forecast of minimum, mean, and maximum temperatures issued at CRATI/ISAC-CNR for the Calabria peninsula (Southern Italy, Fig. 1). Temperature forecasts are produced daily by the Regional Atmospheric Modeling System model (RAMS; Cotton et al., 2003), and this paper shows the forecast performance from 1 December 2008 to 30 November 2009 (365 runs).

Verification of surface temperature forecast is a complicated task because forecast and observation contain different information about the same physical quantities, and this is due to the filtering properties of the numerical weather prediction system in use. In particular, the forecast gives the average of the meteorological parameter over a grid box, and it is representative of the conditions inside the grid box, while surface observations are point measurement.

The difference between the forecast and observation temperatures is particularly important in complex orography and can be accounted by the observation representativeness (or representative) error (Lussana et al., 2010). Representative

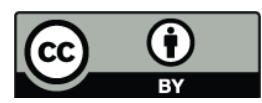

Correspondence to: S. Federico

(s.federico@isac.cnr.it) errors, which are not Gaussian in their distribution and flow dependent, are not instrumental errors but are a component of the observed value due to small scale features that cannot be resolved by the representation of the real world given by the model. They are always defined respect to a model, which in our case is the analyzed field ${ }^{1}$.

The issues related to complex orography and representative errors are certainly important for Calabria, where there is considerable topography variability inside a grid box and where relatively high mountains peaks (1000 m high) are located few kilometres from the shoreline. For example, in presence of the sea-land contrast a sharp temperature gradient develops across the shoreline and differences of several degrees can be reported between two stations located near the coast and few kilometres inland (Simpson, 1994); or, when a cold pool develops, differences of several degrees can be reported by two close stations located, respectively, in a mountain gap and along an adjacent ridge (Myrick et al., 2005). Although the horizontal resolution of modern forecasting system is of the order of $\sim 1-5 \mathrm{~km}$, these differences can occur inside the same grid-box, and the forecast is not able to resolve these small-scale features (Myrick and Horel, 2006, 2008; Mass et al., 2003).

\footnotetext{
${ }^{1}$ The analyzed field depends, in turn, on the error covariances, which determine the scale of the analyzed field.
} 


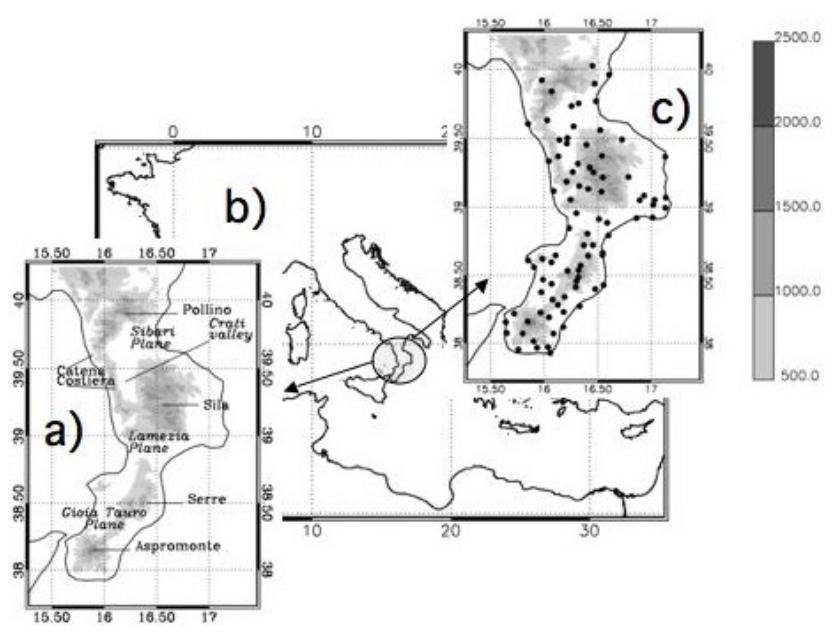

Figure 1. (a) Calabria features cited into the text; (b) Calabria region in the central Mediterranean; (c) Black-filled circles are the stations of the regional network. Grey shading shows the orographic height $(\mathrm{m})$.

Because of the filtering properties of the numerical prediction model, representative errors are here treated as an additional component of the observation error and are filtered out by comparing the forecast with gridded analyses.

The analysis system, its performance in different conditions, and preliminary statistics on the forecast performance were already reported in Federico (2011). This paper, however, presents some new elements, namely: (a) it shows the model performance for a whole year, using a wider dataset, and statistics are more robust; (b) the forecast performance is presented as a function of the season; (c) it uses a different technique to compute the background field.

The paper is divided as follows: Sect. 2 introduces the objective analysis and datasets involved; Sect. 3 presents the forecast statistics, and; Sect. 4 provides conclusions.

\section{The objective analysis and datasets involved}

The observation dataset consists of minimum, mean, and maximum temperature from 87 thermometers (Fig. 1) provided by the Regional Agency for Environmental Protection of Calabria (ARPACAL). The average of the minimum distance between two thermometers is $10 \mathrm{~km}$. The spatial distribution of the 87 thermometers is rather homogeneous and covers both mountains and lowlands ${ }^{2}$.

Data are quality controlled by ARPACAL and it is here assumed that they are not affected by gross measurements errors.

The forecast is issued by the RAMS model (nonhydrostatic). A detailed description of the RAMS model is

\footnotetext{
${ }^{2}$ More information about the automated weather stations of the regional network can be found at www.cfcalabria.it.
}

given in Cotton et al. (2003) while the model settings in the operational context are described in Federico (2011).

Three two-way nested domains with horizontal resolutions of $30 \mathrm{~km}, 7.5 \mathrm{~km}$ and $2.5 \mathrm{~km}$ are used. First domain covers the central part of the Mediterranean basin; the second domain extends over southern Italy; the third domain covers Calabria. For all domains we use thirty vertical levels, up to $16300 \mathrm{~m}$ in the terrain following coordinate system. Levels are not equally spaced: layers within the Planetary Boundary Layer (PBL) are between 50 and $200 \mathrm{~m}$ thick, whereas layers in the middle and upper troposphere are $1000 \mathrm{~m}$ thick.

Atmospheric initial and dynamic boundary conditions, available every $6 \mathrm{~h}$ at $1 \times 1$ degree horizontal resolution, are derived from the 12:00 UTC Global Forecasting System (GFS) run of the National Centres for Environmental Prediction (NCEP; Sela, 1982). A four-dimensional data assimilation technique is used to define the forcing at the lateral boundaries of the five outermost grid cells of the largest domain.

To consider a completely independent dataset for verifying the forecast, the background field is obtained by detrending the observations in the vertical direction, similarly to the methodology of Uboldi et al. (2008). In particular, the vertical temperature gradient is computed for each day and meteorological parameter by performing a least-square minimization of the observations. For example, in the case of mean temperature for the day $i$-th we compute:

$T_{i, \text { mean }}(z)=T_{i, 0 \_ \text {mean }}+\gamma_{i, \text { mean }} z$

where $\gamma_{i, \text { mean }}$ and $T_{i, 0} \_$mean are the parameters computed from the linear fitting and $z$ is the height.

The background field is then reconstructed for each day and meteorological parameter by using the same $2.5 \mathrm{~km}$ digital elevation model (DEM) used by the RAMS, and applying to this DEM the result of the linear fitting. Again, considering the mean temperature for the day $i$-th we have:

$T_{i, \text { mean }}(x, y)=T_{i, 0 \_ \text {mean }}+\gamma_{i, \text { mean }} z_{R}(x, y)$

where $T_{i, \text { mean }}(x, y)$ is the background field, $z_{R}(x, y)$ is the DEM used by the RAMS grid at $2.5 \mathrm{~km}$ horizontal resolution, and $\gamma_{i, \text { mean }}$ and $T_{i, 0 \_ \text {mean }}$ are those of Eq. (1).

The objective analysis implemented, which relies on OI, is described in Federico (2011). In this section we give some details for the paper readability.

The analyzed field, that is the two-dimensional field of minimum, mean or maximum temperature, is given by the equation:

$\boldsymbol{x}_{\mathrm{a}}=\boldsymbol{x}_{\mathrm{b}}+\mathbf{W}\left[\boldsymbol{y}_{\mathrm{o}}-H\left(\boldsymbol{x}_{\mathrm{b}}\right)\right]$

where $\boldsymbol{x}_{\mathrm{a}}$ is the analyzed vector (i.e., the best estimate of the unknown "truth"), $x_{\mathrm{b}}$ is the background (or first guess) field, $\boldsymbol{y}_{\mathrm{o}}$ is the observation vector, whose elements are the measurements of the 87 thermometers, $H$ is the observation operator that transforms the background field into first guesses 
Table 1. Matrices dimensions in the OI algorithm: $n$ (7810) is the grid-points number of the third RAMS domain and $p$ (87) is the number of thermometers.

\begin{tabular}{cc}
\hline Matrix/vector & rows $\times$ columns \\
\hline $\boldsymbol{x}$ & $n \times 1$ \\
$\boldsymbol{y}$ & $p \times 1$ \\
$\mathbf{H}$ & $p \times n$ \\
$\mathbf{W}$ & $n \times p$ \\
$\mathbf{P}$ & $n \times n$ \\
$\mathbf{B}$ & $n \times n$ \\
\hline
\end{tabular}

of the observations, and $\mathbf{W}$ is the optimal weight (or gain) matrix. Matrices dimensions are given in Table 1, where $n$ is the number of grid points of the third RAMS domain (7810) and $p$ is the thermometers number (87).

The gain matrix $\mathbf{W}$ is given by:

$$
\mathbf{W}=\mathbf{B H}^{T}\left(\mathbf{R}+\mathbf{H B H}^{T}\right)^{-1}
$$

where $\mathbf{B}$ and $\mathbf{R}$ are the background and observational error covariance matrices, respectively, and $\mathbf{H}^{T}$ is the transpose of the Jacobian of the forward observation operator (which transforms observation points back to grid points). $\mathbf{H}$ is a bilinear interpolation operator, which accounts for the altitude differences between grid points and stations, through the vertical gradient of the minimum, mean, and maximum temperature. Its formulation is reported in Federico (2011).

The $\mathbf{R}$ and $\mathbf{B}$ matrices depend on the observation $\left(\sigma_{\mathrm{o}}^{2}\right)$ and background $\left(\sigma_{\mathrm{b}}^{2}\right)$ error covariances, respectively, whose magnitudes are estimated by fitting, as a function of the distance $r$, the covariance between observational innovations computed from all background field-observation pairs (Lönnberg and Hollingsworth, 1986; Myrick and Horel, 2006). Assuming that: (a) the observational errors are uncorrelated with one another; and (b) the background and the observational errors are uncorrelated, we obtain the following two equations for the innovations' covariance:

$\operatorname{cov}(r=0)=\sigma_{\mathrm{o}}^{2}+\sigma_{\mathrm{b}}^{2}$

and:

$\operatorname{cov}(r \neq 0)=\sigma_{\mathrm{b}}^{2} \rho(r)$

where $\rho(r)$ is the background error correlation function, which is assumed as an isotropic function of the distance From the data fitting we obtain: $\sigma_{\mathrm{o}}^{2}=0.7,0.4,1.2^{\circ} \mathrm{C}^{2}$ for minimum, mean, and maximum temperature, respectively; $\sigma_{\mathrm{b}}^{2}=1.0,0.6,1.2^{\circ} \mathrm{C}^{2}$ for minimum, mean, and maximum temperature, respectively. The background error correlation function, $\rho(r)$, is a sixth-order polynomial, which minimizes the $\chi^{2}$ among interpolating polynomials ${ }^{3}$.

${ }^{3}$ Polynomials from first to eighth order were tried. Different coefficients of the sixth-order polynomial are used for minimum, mean, and maximum temperature.
Once observation and background error covariances are determined, the matrices $\mathbf{R}$ and $\mathbf{B}$ are easily formed for each parameter. $\mathbf{R}$ is a $p \times p$ diagonal matrix whose elements are all equal to $\sigma_{o}^{2}$. $\mathbf{B}$ is an $n \times n$ matrix whose element $i j$ is the value of the background error correlation function computed for the distance between grid points $i$ and $j$ multiplied by the value $\sigma_{\mathrm{b}}^{2}$.

The analysis error, which by definition quantifies the difference between the analysis and the unknown truth (Kalnay, 2003), is given by the square root of the diagonal elements of the precision matrix $\mathbf{P}_{\mathrm{a}}$. The precision matrix is a $n \times n$ matrix given by:

$\mathbf{P}_{\mathrm{a}}=\left(\mathbf{I}_{n}-\mathbf{W H}\right) \mathbf{B}$

Where $\mathbf{I}_{n}$ is the $n$-dimension identity matrix. It is worth noting that the estimate of the analysis precision is dependent on the statistical estimates/assumptions of the errors being accurate. If the observations and/or background error covariances are poorly known, if there are biases, or if the observations and background errors are correlated, the analysis precision can be considerably worse than implied by Eq. (6).

Before concluding this section it is useful to remark that the grid resolution $(2.5 \mathrm{~km})$ does not correspond to the scale resolution of the analyses, which depends on several factors as the station density and distribution, the parameter considered, and the choices made in specifying the error covariance matrices. In this paper, the distance of the background correlation error is much larger than $2.5 \mathrm{~km}^{4}$, which spreads the observational innovations at distances larger than the grid resolution, smearing small scale features.

While the scale resolution of the analysis is not easy to quantify, it is here stressed that, given the initial assumption on error covariance matrix, the precision matrix returns the bulk estimate of the analysis error to the unknown truth for each grid point, taking into account for the different factors determining the analysis resolution scale.

\section{Results}

Cumulative statistics are reported in Table 2 and show the bias, the Mean Absolute Error (MAE) and the RMSE for the whole period averaged for the land grid points of the third model domain ${ }^{5}$. For example the RMSE reported in Table 2 for each parameter and forecast day is given by:

$\operatorname{RMSE}=\frac{1}{N} \sum_{i=1}^{N} \sqrt{\frac{1}{N_{\mathrm{d}}} \sum_{k=1}^{N_{\mathrm{d}}}\left(T_{k}-A_{k}\right)^{2}}$

${ }^{4}$ In this paper we do not show the detail of the Lönnberg and Hollingsworth method, and the reader is referred to Federico (2011). However, the data show that innovations are correlated for distances of the order of $30 \mathrm{~km}$.

${ }^{5} \mathrm{We}$ consider land grid-points only because measurements are available over the land. 
Table 2. Bias $\left({ }^{\circ} \mathrm{C}\right)$, MAE $\left({ }^{\circ} \mathrm{C}\right)$, and RMSE $\left({ }^{\circ} \mathrm{C}\right)$ averaged for land grid points respect to the analyses. Values for each grid point are computed for the whole period. The rows show the results of each forecast day. Min, med, and max refers to minimum, mean and maximum temperature, respectively. The analysis error is shown only for the first-day and is equal for all days. The values in parentheses are the statistics for the analyses grid-points nearest to the observations. Shaded rows: statistics computed respect to ROI-analyses. The first-day ROI row (in italic) is not intended for verification purposes but shows the performance of the OI scheme using the RAMS first-day forecast as background field.

\begin{tabular}{|c|c|c|c|c|c|c|c|c|c|}
\hline & $\begin{array}{l}\text { Bias } \\
\text { min }\end{array}$ & $\begin{array}{l}\text { Bias } \\
\text { med }\end{array}$ & $\begin{array}{l}\text { Bias } \\
\max \end{array}$ & $\begin{array}{l}\text { MAE } \\
\min \end{array}$ & $\begin{array}{l}\text { MAE } \\
\text { med }\end{array}$ & $\begin{array}{l}\text { MAE } \\
\max \end{array}$ & $\begin{array}{l}\text { RMSE } \\
\text { min }\end{array}$ & $\begin{array}{l}\text { RMSE } \\
\text { med }\end{array}$ & $\begin{array}{l}\text { RMSE } \\
\max \end{array}$ \\
\hline $1 \mathrm{D}$ & $\begin{array}{l}-1.0 \pm 0.8 \\
(-0.8)\end{array}$ & $\begin{array}{l}-0.6 \pm 0.6 \\
(-0.5)\end{array}$ & $\begin{array}{l}0.0 \pm 0.9 \\
(-0.1)\end{array}$ & $\begin{array}{l}1.6 \pm 0.8 \\
(1.5)\end{array}$ & $\begin{array}{l}1.2 \pm 0.6 \\
(1.2)\end{array}$ & $\begin{array}{l}1.6 \pm 0.9 \\
(1.7)\end{array}$ & $\begin{array}{l}1.9 \pm 0.8 \\
(1.9)\end{array}$ & $\begin{array}{l}1.5 \pm 0.6 \\
(1.6)\end{array}$ & $\begin{array}{l}2.1 \pm 0.9 \\
(2.2)\end{array}$ \\
\hline $2 \mathrm{D}$ & $\begin{array}{l}-1.0 \\
(-0.8)\end{array}$ & $\begin{array}{l}-0.7 \\
(-0.7)\end{array}$ & $\begin{array}{l}-0.2 \\
(-0.3)\end{array}$ & $\begin{array}{l}1.6 \\
(1.6)\end{array}$ & $\begin{array}{l}1.4 \\
(1.4)\end{array}$ & $\begin{array}{l}1.8 \\
(1.8)\end{array}$ & $\begin{array}{l}2.0 \\
(2.0)\end{array}$ & $\begin{array}{l}1.7 \\
(1.7)\end{array}$ & $\begin{array}{l}2.3 \\
(2.4)\end{array}$ \\
\hline $3 \mathrm{D}$ & $\begin{array}{l}-1.0 \\
(-0.8)\end{array}$ & $\begin{array}{l}-0.7 \\
(-0.7)\end{array}$ & $\begin{array}{l}-0.2 \\
(-0.3)\end{array}$ & $\begin{array}{l}1.7 \\
(1.6)\end{array}$ & $\begin{array}{l}1.4 \\
(1.4)\end{array}$ & $\begin{array}{l}1.8 \\
(1.9)\end{array}$ & $\begin{array}{l}2.1 \\
(2.1)\end{array}$ & $\begin{array}{l}1.8 \\
(1.7)\end{array}$ & $\begin{array}{l}2.4 \\
(2.4)\end{array}$ \\
\hline $1 D-R O I$ & $\begin{array}{l}-0.6 \pm 0.9 \\
(-0.5)\end{array}$ & $\begin{array}{l}-0.4 \pm 0.8 \\
(-0.4)\end{array}$ & $\begin{array}{l}-0.1 \pm 1.1 \\
(-0.1)\end{array}$ & $\begin{array}{l}1.0 \pm 0.9 \\
(1.0)\end{array}$ & $\begin{array}{l}0.8 \pm 0.8 \\
(0.8)\end{array}$ & $\begin{array}{l}1.0 \pm 1.1 \\
(1.0)\end{array}$ & $\begin{array}{l}1.2 \pm 0.9 \\
(1.3)\end{array}$ & $\begin{array}{l}1.0 \pm 0.8 \\
(1.1)\end{array}$ & $\begin{array}{l}1.3 \pm 1.1 \\
(1.4)\end{array}$ \\
\hline 2D-ROI & $\begin{array}{l}-0.6 \\
(-0.5)\end{array}$ & $\begin{array}{l}-0.5 \\
(-0.5)\end{array}$ & $\begin{array}{l}-0.3 \\
(-0.4)\end{array}$ & $\begin{array}{l}1.2 \\
(1.2)\end{array}$ & $\begin{array}{l}1.0 \\
(1.0)\end{array}$ & $\begin{array}{l}1.4 \\
(1.3)\end{array}$ & $\begin{array}{l}1.6 \\
(1.6)\end{array}$ & $\begin{array}{l}1.3 \\
(1.4)\end{array}$ & $\begin{array}{l}1.9 \\
(1.8)\end{array}$ \\
\hline 3D-ROI & $\begin{array}{l}-0.6 \\
(-0.6)\end{array}$ & $\begin{array}{l}-0.5 \\
(-0.5)\end{array}$ & $\begin{array}{l}-0.3 \\
(-0.3)\end{array}$ & $\begin{array}{l}1.4 \\
(1.3)\end{array}$ & $\begin{array}{l}1.1 \\
(1.1)\end{array}$ & $\begin{array}{l}1.6 \\
(1.4)\end{array}$ & $\begin{array}{l}1.8 \\
(1.8)\end{array}$ & $\begin{array}{l}1.5 \\
(1.5)\end{array}$ & $\begin{array}{l}2.1 \\
(2.0)\end{array}$ \\
\hline
\end{tabular}

where $T_{k}$ is the temperature forecast for the day $k$-th, $A_{k}$ is the corresponding analysis, $N_{\mathrm{d}}$ is the number of days (365), $N$ is the number of land grid points of the third RAMS domain.

The bias is negative for all parameters and forecast days showing that the forecast is colder than analysis on average. The MAE shows a good performance because the error it is below $2{ }^{\circ} \mathrm{C}$ for all parameters and forecast days. The RMSE shows also good performance being about $2{ }^{\circ} \mathrm{C}$ for minimum and mean temperature for the third forecast day, which scores the worst. For maximum temperature, RMSE varies from 2.1 to $2.4^{\circ} \mathrm{C}$ from the first to the third day.

As noticed in the introduction, the use of gridded analyses is motivated by the filtering of small scales features that cannot be represented by the numerical weather prediction system in use. The filtering properties of the OI scheme are determined by the error covariances, which were computed using an observation-based field as background (hereafter we will refer to these analyses as OI-analyses). These filtering properties may not match those of the numerical model and it is interesting to show the cumulative statistics respect to OI analyses using the RAMS first day forecast as background field (hereafter ROI-analyses) ${ }^{6}$. These statistics cannot quantify the forecast error for the first-day forecast because analyses and forecasts are statistically dependent.

\footnotetext{
${ }^{6}$ The parameters of the OI scheme were determined by the Lönnberg and Hollingsworth method giving: $\sigma_{\mathrm{o}}^{2}=1.1,0.5,1.2^{\circ} \mathrm{C}^{2}$ for minimum, mean, and maximum temperature, respectively; and $\sigma_{\mathrm{b}}^{2}=1.5,1.5,2.7^{\circ} \mathrm{C}^{2}$ for minimum, mean, and maximum temperature, respectively.
}

Table 2 shows that forecast errors decrease when compared to ROI-analyses. This is expected because: (a) the filtering properties of the ROI-analyses match better those of the numerical model; (b) as we didn't attempt to remove the forecast bias, the ROI-analyses have a small bias respect to OI-analyses (absolute value less than $0.5^{\circ} \mathrm{C}$ for all parameters when averaged over the entire domain), which improves the forecast error.

It is also interesting to note that the ROI-analysis error is larger than OI-analysis using de-trended fields because the innovations, i.e. the differences between the background at the observation locations and the observations, are larger for ROI-analyses. So, the better forecast skill respect to ROIanalyses is partially compensated by the larger error of the ROI-analyses respect to the unknown truth, given the initial assumption on error covariances.

The statistics of Table 2 refer to all land grid points of the third domain. Because the grid cells containing at least one station correspond to less than $3 \%$ of the land grid points, it is interesting to consider the verification over the small fraction of the grid-points adjacent to observation locations. These statistics are reported in Table 2 and show small differences compared to the statistics over the whole domain. This result is not surprising because local features are smoothed by the OI scheme and stations are rather homogeneously distributed over the country. 


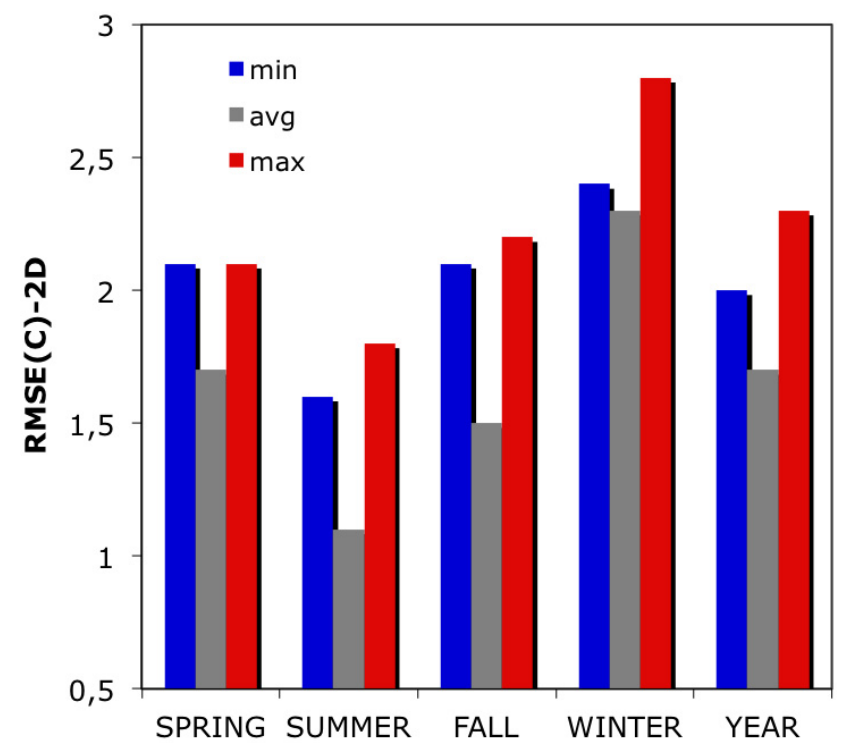

Figure 2. $\operatorname{RMSE}\left({ }^{\circ} \mathrm{C}\right)$ seasonal distribution for minimum (min), mean (avg), and maximum (max) temperature.

Thereafter, we will consider the statistics for the secondday forecast and for the whole (land) domain because: (a) the second day scores between the first and third day and it is representative of the whole forecast behaviour; (b) the results for the subset of grid points nearest to the observations and for the whole domain are similar, as shown by the results of Table 2. Statistics are shown against OI-analyses because they give a conservative estimate of the forecast error.

To analyze the model performance with season, Fig. 2 shows the land averaged RMSE for minimum, mean, and maximum temperature, for different seasons and for the second-day forecast. Spring contains statistics for MAM, summer for JJA, fall for SON and winter for DJF. The December month is taken from 2008.

Summer has the best performance while winter scores the worst. For example, mean temperature RMSE is $1.1^{\circ} \mathrm{C}$ for summer and $2.3^{\circ} \mathrm{C}$ for winter. Spring and fall errors are between those of summer and winter. Comparing spring and fall it follows that the former scores better for maximum temperature while the latter has a lower error for mean temperature.

Previous result is expected considering the Mediterranean characteristics of the Calabria climate (Colacino, 1990; Federico et al., 2009). In summer the weather is stable and fair and its predictability is expected longer; in winter the incidence of synoptic scale cyclones is the highest and forecast errors are larger in these conditions.

The spatial distribution of the RMSE is shown in Fig. 3a for mean temperature and for the second day forecast. First we remark the rather good performance of the forecast because RMSE is less than $1.5^{\circ} \mathrm{C}$ for more than half of the domain area. The largest error occurs in the Crati valley and in
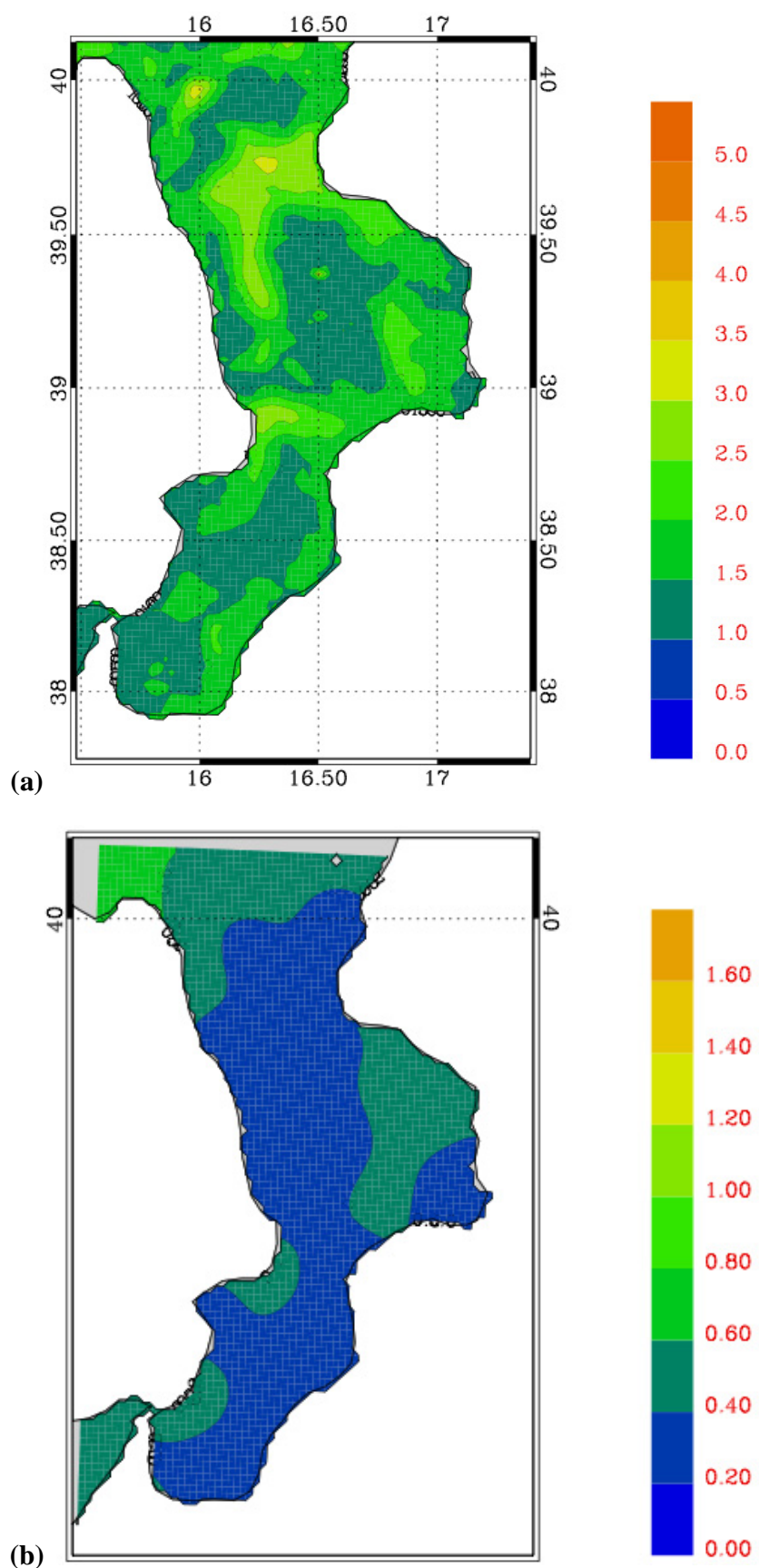

Figure 3. (a) Mean temperature RMSE $\left({ }^{\circ} \mathrm{C}\right)$ for the second-day forecast; (b) averaged precision $\left({ }^{\circ} \mathrm{C}^{2}\right)$ for mean temperature.

the Sibari Plain where RMSE is larger than $2.0-2.5^{\circ} \mathrm{C}$ with a maximum of more than $3.0^{\circ} \mathrm{C}$ in the plain centre. Errors are lower than $1.5^{\circ} \mathrm{C}$ in southern Calabria (roughly south of $39^{\circ} \mathrm{N}$ ), over the Sila plateau, and for northwest Calabria.

It is interesting to note that areas with larger RMSE are colocated with well-defined topographical features: the Crati valley and Sibari Plain, the Lamezia Terme Plain, and the deep small valley in northwest Calabria (Lao river valley). 
The reason for this issue is that the forecast smears the meteorological features in these valleys, and the $2.5 \mathrm{~km}$ horizontal resolution is still not enough to represent several local phenomena induced by the physiographical features of Calabria, as the sharp temperature gradient across the shoreline or along the slopes of the ridges surrounding the plains. It is also interesting to point out the two local error maxima over the Sila plateau. They correspond to the two main lakes of Calabria (Cecita and Arvo) and are likely caused by an overestimation of the water surface temperature in the initial field used by the meteorological model. Work is in progress to assess this point.

To gain a complete knowledge of the RMSE spatial patterns, Fig. 3b shows the precision of the analysis for mean temperature averaged for the whole period. The square root of Fig. $3 \mathrm{~b}$ gives the analysis error.

The analysis error is larger in data void areas, namely northern Calabria and the eastern flank of the Sila, and its value is modulated by the gain matrix and the background error by Eq. (6). Comparing Fig. 3a and $b$ we note that the model performance is particularly good for southern Calabria and for the western Sila plateau because they are data rich regions and the analysis and forecast RMSE are low.

Root mean square error patterns for other days and for other parameters are similar to Fig. 3a (not shown) and errors are lower/larger than Fig. 3a depending on the forecast day and on the parameter considered, according to the results of Table 2.

\section{Conclusions}

This paper shows the verification of a high-resolution surface temperature forecast for one climatological year (1 December 2008-30 November 2009) in Calabria.

There is a main issue in verifying the forecast in complex terrain because forecast and observation contain different information about the same physical quantities and this is due to the filtering properties of the numerical weather prediction system in use. To cope with this issue, we compare the forecast with analyses of surface temperature, which are representative of the average conditions inside the grid box and are ideally equal to the average of an infinite number of unbiased observations inside the grid box. Analyses are generated by optimal interpolation. The background field is obtained by de-trending the observations in the vertical direction, and reconstructing the field by the digital elevation model of the numerical weather prediction model.

The analysis algorithm and some example of analysis were already reported in the bibliography (Federico, 2011), and the aim of this paper is to quantify model errors using a wider and different dataset, which is more relevant for statistical and climatic considerations, as well as to present new statistics.
Verification of surface temperature forecast is a high dimensional problem and cumulative statistics are used to quantify the forecast performance. Mean absolute error and RMSE show good results. The largest error is for maximum temperature, whose RMSE varies from $2.1^{\circ} \mathrm{C}$ to $2.4^{\circ} \mathrm{C}$ from the first- to the third-day forecast.

The seasonal dependence of the error is modulated by the Mediterranean characteristics of the Calabria climate. Errors are the smallest in summer, when the weather is fair and stable, while they are the largest in winter, which has the maximum incidence of synoptic-scale cyclones.

The RMSE spatial pattern highlights areas with larger (lower) errors. Southern Calabria has the smallest errors, while the largest errors are co-located with three main topographical features: the Crati valley and Sibari Plain, the Lamezia Terme Plain, and Lao river valley. The forecast inspection shows that errors are caused by the smearing of the meteorological features induced by local physiographical features of Calabria and that the $2.5 \mathrm{~km}$ horizontal resolution is still not enough to represent the sharp temperature gradients generated by those features. Errors patterns are similar for all forecast days and were also found in Federico (2011) for a different dataset, thus revealing areas in which the model forecast need to be improved the more.

The analysis error, which quantifies the difference between the analyzed field and the unknown truth, given the initial assumption on error covariance matrix, increases in data void areas and takes into account for the several factors determining the analysis scale.

Acknowledgements. This work was partially funded by the project "MAPVIC - Modellistica Agrometeorologia di Precisione per la Viticoltura Calabrese" funded by the Calabria Region. The Regional Agency for Environmental Protection (ARPACAL) is acknowledged for the regional network data. We are grateful to the reviewers who helped to improve the quality of the paper.

Edited by: O. E. Tveito

Reviewed by: three anonymous referees

SC $\mid$ nat $\$ \begin{aligned} & \text { The publication of this article is sponsored } \\ & \text { by the Swiss Academy of Sciences. }\end{aligned}$

\section{References}

Colacino, M.: Mediterranean Meteorology, in: Proceedings NATOASI, edited by: Charnock, H., Reports in Meteorology and Oceanography, 40, 1-38, 1990.

Cotton, W. R., Pielke Sr., R. A., Walko, R. L., Liston, G. E., Tremback, C. J., Jiang, H., McAnelly, R. L., Harrington, J. Y., Nicholls, M. E., Carrio, G. G., and McFadden, J. P.: RAMS 2001: Current status and future directions, Meteor. Atmos., Phys., 82, 5-29, 2003.

Federico, S.: Verification of surface minimum, mean, and maximum temperature forecasts in Calabria for summer 2008, Nat. Hazards Earth Syst. Sci., 11, 487-500, doi:10.5194/nhess-11487-2011, 2011. 
Federico, S., Avolio, E., Pasqualoni, L., De Leo, L., Sempreviva, A. M., and Bellecci, C.: Preliminary results of a 30-year daily rainfall data base in southern Italy, Atmos. Research, 94, 641651, doi:10.1016/j.atmosres.2009.03.008, 2009.

Kalnay, E.: Atmospheric Modeling, Data Assimilation and Predictability, Cambridge University Press, 2003.

Lönnberg, P. and Hollingsworth, A.: The statistical structure of short-range forecast errors as determined from radiosonde data. Part II: The covariance of height and wind errors, Tellus, 38A, 137-161, 1986.

Lussana, C., Uboldi, F., and Salvati, M. R.: A spatial consistency test for surface observations from mesoscale meteorological networks, Q. J. Roy. Meteor. Soc., 136, 1075-1088, 2010.

Mass, C. F., Albright, M., Ovens, D., and coauthors: Regional Environmental Prediction Over the Pacific Northwest, B. Am. Meteorol. Soc., 84(10), 1353-1366, 2003.
Myrick, D. T. and Horel, J. H.: Verification of surface temperature from the National Digital Forecast Database over the western United States, Weather Forecast., 21, 869-892, 2006.

Myrick, D. T. and Horel, J. H.: Sensitivity of Surface Analyses over the Western United States to RAWS Observations, Weather Forecast., 23, 145-158, 2008.

Myrick, D. T., Horel, J. D., and Lazarus, S. M.: Local adjustment of the background error correlation for surface analyses over complex terrain, Weather Forecast., 20, 149-160, 2005.

Simpson, J. E.: Sea breeze and local winds, Cambridge University Press, Cambridge, 1994.

Sela, J. G.: The NMC Spectral Model, NOAA Tech. Rep. NWS-30, 36 pp., 1982.

Uboldi, F., Lussana, C., and Salvati, M: Three-dimensional spatial interpolation of surface meteorological observations from highresolution local networks, Meteorol. Appl., 15, 331-345, 2008. 